Vol 11, Issue 11, 2018

\title{
EFFECT OF MURRAYA KOENIGII LEAVES EXTRACT ON GLUCONEOGENESIS AND GLYCOGENOLYSIS IN ISOLATED RAT HEPATOCYTES CULTURE
}

\author{
ROHAN S PHATAK ${ }^{1 *}$, CHITRA C KHANWELKAR ${ }^{1}$, KAILAS D DATKHILE ${ }^{2}$, PRATIK P DURGAWALE ${ }^{2}$ \\ ${ }^{1}$ Department of Pharmacology, Krishna Institute of Medical Sciences, Karad, Maharashtra, India. ${ }^{2}$ Department of Molecular Biology and \\ Genetics, Krishna Institute of Medical Sciences, Karad, Maharashtra, India. Email: phatak.rohan1983@gmail.com
}

Received: 15 June 2018, Revised and Accepted: 09 July 2018

\section{ABSTRACT}

Objectives: The present study was aimed to investigate the in vitro activity of Murraya koenigii extracts through various carbohydrate metabolic pathways in the isolated rat hepatocyte models.

Methods: Different doses of metformin, aqueous and methanol extracts of M. koenigii leaves were evaluated in the MTT, glucose, and glycogen content assays in the cultured in vitro rat hepatocytes.

Results: The study showed that there was a significant increase in activity with respect to the increased concentration of extracts. Slight effect was observed in the isolated rat hepatocytes culture, M. koenigii leaves extract may exert cytoprotective and hypoglycemic action.

Conclusion: It may be needed to determine the effect of ex vivo rat hepatocytes isolated from diabetic rats. Effects of the plant or isolated compounds on the genes expression of signaling pathways should be investigated in further studies.

Keywords: Murraya koenigii, Non-insulin-dependent diabetes mellitus, Gluconeogenesis, Glycogenolysis.

(C) 2018 The Authors. Published by Innovare Academic Sciences Pvt Ltd. This is an open access article under the CC BY license (http://creativecommons. org/licenses/by/4. 0/) DOI: http://dx.doi.org/10.22159/ajpcr.2018.v11i11.27962

\section{INTRODUCTION}

Non-insulin-dependent diabetes mellitus (NDDM) or type 2 diabetes mellitus is the most common metabolic syndrome spreading throughout the world [1]. Gluconeogenesis plays a key role to prevent an extreme decline in the blood glucose level during fasting. Augmented hepatic gluconeogenesis is the significant contributing factor to the fasting hyperglycemia which is found in NDDM patients [1,2]. Liver maintains blood glucose levels during fasting through mainly two metabolic pathways by glycogenolysis, i.e., converting its stored glycogen into glucose and by gluconeogenesis, i.e., synthesizing glucose mainly from lactate and amino acids [3]. Failure or lack of insulin secretion or action is the main characteristic of insulin resistance. It involves in both muscle and liver as characteristic features of the glucose intolerance in NDDM individuals. Basically liver holds a major position of insulin resistance, so the overproduction of glucose is reflected despite the presence of both fasting hyperinsulinemia and hyperglycemia [4].

Since there is a shortage of scientific evidence in the review of literature for the effect of Murraya koenigii leaves extract on the gluconeogenesis [2], whether it suppresses the generation of glucose. The aim of our study was to test the hypothesis that whether M. koenigii leaves extract inhibits the glucose by inhibiting gluconeogenesis and suppressing glycogenolysis in the cultured rat hepatocytes.

\section{METHODS}

\section{Drugs and chemicals}

Metformin was purchased from Sigma-Aldrich Ltd. Hank's Balanced Salt Solution, Liver digest medium (17701-038), Hepatocyte wash medium (17704-024), Williams E medium (A12176), Fetal Bovine Serum (2614079), Penicillin,-streptomycin (15140-122), and Trypan blue stain (15250) were purchased from Gibco, Thermo Scientific Ltd. Dimethyl sulfoxide (DMSO) (D2650) was purchased from SigmaAldrich, Ltd. USA, MTT (M6494) from Invitrogen, Thermo Scientific, USA, 6 well plates (CLS3355), 96 well plates (CLS3599), and $5 \mathrm{~mL}$ stereopipettes (CLS4487) were purchased from Corning, New York,
USA. All reagents and chemicals used were of analytical grade and stored in a refrigerator at $+4^{\circ} \mathrm{C}$. The reagents were equilibrated at room temperature for $30 \mathrm{~min}$ before the start of the analysis.

\section{Collection and authentication of plant material}

Leaves of $M$. koenigii were collected from the local area of Karad in Maharashtra, India $\left(17.2760^{\circ} \mathrm{N}, 74.2003^{\circ} \mathrm{E}\right)$, certified and authenticated by the Department of Botany, M. S. Shinde Mahavidyalaya, Tisangi, Kolhapur, India. The plant specimen voucher V03 (Ref: MHST/2016-17/28) of the plant was deposited in the herbarium. Fresh leaves were purchased from the local market of Karad, washed under tap water thoroughly; dried under shade and powdered using a mechanical grinder.

Preparation of $M$. koenigii leaves extracts

Methanolic (MEMK) and aqueous (AEMK) extracts of M. koenigii leaves were prepared by soxhletation method. Extracts were concentrated in a vacuum rotary evaporator and air evaporated.

\section{Experimental animals}

Healthy Wistar rats of either sex, weighing between 170 and $200 \mathrm{~g}$ were used in the study. Experiment study was conducted with the guidelines of Committee for the Purpose of Control and Supervision of Experiments on Animals (CPCSEA) for animal experimentation of laboratory and Institutional Animal Ethics Committee (Reg. No. 255/PO/2000/bc/CPCSEA), Krishna Institute of Medical Sciences, Karad, has approved the study.

\section{Rat hepatocyte culture preparation}

The method of rat hepatocytes culture was modified and prepared in accordance with Shen et al. [5].

\section{Rat dissection and isolation of liver}

Rats of either sex $200 \mathrm{~g}$ body weight were anesthetized in diethyl ether chamber. Depth of anesthesia was monitored by toe pinch. Hepatic portal vein was exposed by carefully moving the viscera to the right outside of 
the abdominal cavity. After saline perfusion, the liver was dissected and placed in a pre-chilled sterile beaker with $20 \mathrm{~mL}$ HBSS medium.

\section{Hepatocyte isolation}

In the biosafety cabinet Type II, the liver tissue was washed thoroughly with HBSS containing penicillin/streptomycin to remove blood stains. The tissue was dissected into small pieces with a surgical blade and scraped to release cells into the buffer. Tissue pieces were transferred into sterile $15 \mathrm{~mL}$ centrifuge tube along with HBSS buffer containing penicillin-streptomycin (100 units/mL/100 $\mu \mathrm{g} / \mathrm{mL}$ ) antibiotics and washed 2-3 times by centrifugation at $1000 \mathrm{~g}$ for $5 \mathrm{~min}$. Then, liver tissue pieces were digested with an appropriate volume of liver digest medium containing collagenase - I and dispase - II for $2 \mathrm{~h}$. The dispersed hepatocytes into single cell suspension were filtered through a $100 \mu \mathrm{m}$ pore size cell strainer into a $50 \mathrm{~mL}$ conical tube to remove connective tissues and undigested tissue fragments. The single cell suspension was washed with ice-cold hepatocyte wash medium for 2-3 times. The purified hepatocytes in cell pellets were re-suspended in $40 \mathrm{~mL}$ William's E Medium supplemented with $1 \mathrm{~mL}$ of penicillinstreptomycin and determined viable cell density by cell viability by Trypan blue staining.

\section{Hepatocyte culture}

The hepatocytes with 95-98\% cell viability were grown in Williams E medium supplemented with $10 \%$ fetal bovine serum and penicillin/ streptomycin (100 units $/ \mathrm{mL} / 100 \mu \mathrm{g} / \mathrm{mL}$ ) antibiotics. It was diluted cells with William's E medium to the required concentration. In $25 \mathrm{~mL}$ capacity Nunc cell culture flask containing $5 \mathrm{~mL}$ of William's E medium supplemented with $10 \%$ fetal bovine serum (FBS) and $100 \mu \mathrm{L}$ of penicillin and streptomycin, $1 \times 10^{8}$ cells were seeded and maintained in a $\mathrm{CO}_{2}$ incubator at $37^{\circ} \mathrm{C}$ in $95 \%$ humidity and $5 \% \mathrm{CO}_{2}$. After $24 \mathrm{~h}$ culture incubation, the cells were maintained in the medium with serum-free medium. The serum-free medium helped to maintain cell morphology with no adverse effects from hormones when the serumfree medium was used.

\section{Cell viability in isolated rat hepatocytes by MTT method}

Cell viability assay was performed according to the method described by Mosmann T [6]. In vitro cytotoxicity effects of the metformin, AEMK and MEMK on hepatocytes were determined by MTT assay. The cells were maintained in Williams E medium supplemented with $10 \%$ FBS, penicillin-streptomycin at $100 \mathrm{U} / \mathrm{mL} / 100 \mu \mathrm{g} / \mathrm{mL}$ in a humidified atmosphere of $5 \% \mathrm{CO}_{2}$ at $37^{\circ} \mathrm{C} .10,000$ cells were seeded in a 96 well plate and incubated at $37^{\circ} \mathrm{C}, 5 \% \mathrm{CO}_{2}$. After $24 \mathrm{~h}$ of incubation, the cells were exposed to the treatment of AEMK and MEMK at concentrations of $1,2.5,5$, and $10 \mathrm{mg} / \mathrm{mL}$ in culture medium without FBS and incubated for further $24 \mathrm{~h}$ at $37^{\circ} \mathrm{C}$ and $5 \% \mathrm{CO}_{2}$. After $24 \mathrm{~h}$ completion of treatment, cells were washed with sterile HBSS medium; thereafter, cell viability was determined using MTT dye. In $10 \mu \mathrm{L} /$ well, MTT ( $5 \mathrm{mg} / \mathrm{mL})$ was added to the cells, and the plates were further incubated at $37^{\circ} \mathrm{C}$, and $5 \%$ $\mathrm{CO}_{2}$ atmosphere. After $4 \mathrm{~h}$ incubation, the MTT solution was carefully removed, and $200 \mu \mathrm{L}$ of DMSO was added to each well. The absorbance of purple color developed was measured at $560 \mathrm{~nm}$ wavelength using UV-visible 1800 spectrophotometer (Shimadzu). The results were expressed as a percentage of cell survival as compared to the control. All experiments were performed in triplicates.

\section{Glucose assay in isolated rat hepatocytes}

Glucose assay was assessed by the method of Yan et al. [7]. Cells were cultured in collagen M199 medium supplemented with 5\% FBS, $100 \mathrm{IU} / \mathrm{mL}$ of penicillin, and $100 \mu \mathrm{g} / \mathrm{mL}$ of streptomycin in a 12well plate and treated with metformin $(0.1-1 \mathrm{mg} / \mathrm{mL})$ and extracts (10-1 $\mathrm{mg} / \mathrm{mL}$ ) for $24 \mathrm{~h}$. After centrifugation, the supernatant medium was collected, and glucose concentration was measured with a DNS reagent. Absorbance was determined at $540 \mathrm{~nm}$ [7].

Glycogen content assay in isolated rat hepatocytes

Glycogen content assay was assessed by the method of Yan et al. [7]. Cells were seeded in a 6-well plate and treated with metformin
(0.1-1 $\mathrm{mg} / \mathrm{mL})$ and extracts $(10-1 \mathrm{mg} / \mathrm{mL})$ for $24 \mathrm{~h}$. Cells were collected and adjusted to the same concentration. The cells were then homogenized using $0.5 \mathrm{~mL}$ of $30 \%(0.3 \mathrm{~g} / \mathrm{mL})$ potassium hydroxide and boiled for $15 \mathrm{~min}$ to destroy glucose, followed by centrifugation at $15,000 \mathrm{~g}$ for $15 \mathrm{~min}$ after adding $1.5 \mathrm{~mL}$ ethyl alcohol. The precipitates were dissolved in $0.5 \mathrm{~mL}$ of distilled water and boiled for $20 \mathrm{~min}$ after adding $0.2 \%$ anthrone diluted with $98 \% \mathrm{H}_{2} \mathrm{SO}_{4}$. The glycogen content was determined using the anthrone reagent. The absorbance was detected at $620 \mathrm{~nm}$ [7]

\section{Statistical analysis}

Data were expressed as the mean \pm standard deviation. Data analysis was performed using GraphPad Prism 5.0 software (GraphPad, San Diego, CA). All data were analyzed using two-way repeated analysis of variance, and Tukey's test was applied for post hoc analysis. The value of $\mathrm{p}<0.05$ was considered to be statistically significant.

\section{RESULTS}

It showed that the findings increase with respect to the increased concentration of extracts. Since there was a slight effect observed in the isolated rat hepatocytes culture, it may be needed to determine the effect of ex vivo rat hepatocytes isolated from diabetic rats. It was observed extremely significant $(\mathrm{p}=0.0054)$ in MTT assay as shown in Fig. 1 while was found to be significant in glucose $(p=0.0196)$ and glycogen $(\mathrm{p}=0.0218)$ assays as shown in Tables 1 and 2 .

\section{DISCUSSION}

Glucose is the fundamental source of energy for the vital organs such as brain, heart, and red blood cells. It is stored in the form of glycogen in the liver and skeletal muscle. In NDDM, the failure of suppressing gluconeogenesis results in decreased liver glycogen storage in the postprandial state [4] along with reduced glucose deposition in skeletal muscle, heart, and adipose tissue [1].

Pyruvate-dependent gluconeogenesis involves in converting pyruvate to phosphoenol pyruvate by the enzyme phosphoenolpyruvate carboxykinase (PEPCK) present in the cytosol, and mitochondrial dicarboxylic acids are also involved [4]. Insulin inhibits gluconeogenesis by suppressing two rate-limiting gene expressions of PEPCK and glucose6-phosphatase (G6Pase) while glucagon stimulates both genes, PEPCK, and G6Pase [1]. The enzyme G6Pase converts G6Pase to glucose as a final step in the metabolic pathways of glycogenolysis and gluconeogenesis. Thus, inhibiting this enzyme reduces hepatic glucose output [3]

Gluconeogenesis is involved in the conversion of carbohydrate as well as non-carbohydrate precursors to glucose or glycogen. G6Pase and

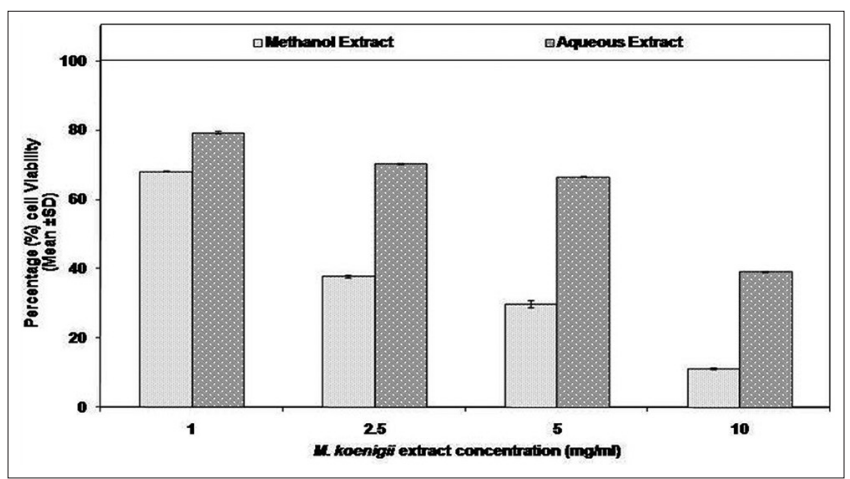

Fig. 1: Representative histogram showing the percentage cell viability of rat hepatocytes exposed to different concentrations $(1,2.5,5$, and $10 \mathrm{mg} / \mathrm{mL})$ of methanol and aqueous extract of Murraya koenigii leaves measured by MTT assay. The results represent the means of three independent experiments and error bars represent the standard deviation of the means 
Table 1: Effect of M. koenigii on glucose content in isolated rat hepatocytes

\begin{tabular}{lllll}
\hline Concentration $(\mathrm{mg} / \mathrm{mL})$ & MEMK & AEMK & Concentration $(\mathrm{mg} / \mathbf{m L})$ & MET \\
\hline 10 & $0.67 \pm 0.09$ & $0.71 \pm 0.007$ & 1 & $0.037 \pm 0.001$ \\
5 & $0.58 \pm 0.04$ & $0.45 \pm 0.008$ & 0.5 & $0.047 \pm 0.005$ \\
2.5 & $0.37 \pm 0.07$ & $0.26 \pm 0.007$ & 0.25 & $0.049 \pm 0.001$ \\
1 & $0.26 \pm 0.03$ & $0.14 \pm 0.001$ & 0.1 & $0.048 \pm 0.003$ \\
\hline
\end{tabular}

Values are expressed in mean \pm SD, MET: Metformin, AEMK: Aqueous extract of M. koenigii leaves, MEMK: Methanolic extract of M. koenigii leaves,

$\mathrm{p}=0.0196$, M. koenigii: Murraya koenigii

Table 2: Effect of M. koenigii on glycogen content in isolated rat hepatocytes

\begin{tabular}{lllll}
\hline Concentration $(\mathrm{mg} / \mathrm{mL})$ & MEMK & AEMK & Concentration $(\mathrm{mg} / \mathrm{mL})$ & MET \\
\hline 10 & $0.053 \pm 0.001$ & $0.141 \pm 0.001$ & 1 & $0.018 \pm 0.001$ \\
5 & $0.072 \pm 0.001$ & $0.100 \pm 0.001$ & 0.5 & $0.015 \pm 0.001$ \\
2.5 & $0.029 \pm 0.001$ & $0.052 \pm 0.001$ & 0.25 & $0.014 \pm 0.002$ \\
1 & $0.026 \pm 0.001$ & $0.049 \pm 0.0005$ & 0.1 & $0.019 \pm 0.002$ \\
\hline
\end{tabular}

Values are expressed in mean \pm SD, MET: Metformin, AEMK: Aqueous extract of $M$. koenigii leaves, MEMK: Methanolic extract of $M$. koenigii leaves, $\mathrm{p}=0.0218$,

M. koenigii: Murraya koenigii

fructose-1, 6-disphosphnatase (F1-6DPase) are the important regulatory enzymes in the gluconeogenic pathway. Both get altered in uncontrolled diabetes. G6Pase catalyzes the conversion of G6Pase splitting to glucose and hydrogen, which binds with NADP+ in the form of NADPH and enhances the synthesis of fats from carbohydrates, i.e., lipogenesis. The generation of fructose-6-phosphate from fructose-1, 6-diphosphate is catalyzed by F1-6DPase. The activities of these two enzymes are increased in the diabetic control rats compared with the normal rats [8].

Decreased glycolysis, impeded glycogenesis and increased gluconeogenesis are some of the changes in glucose metabolism in the diabetic liver. In the present study, M. koenigii could be proven to inhibit glucose inhibition which is in accordance with the study by Cheng et al., [9]. Cinnamon aqueous extract and its polyphenolics demonstrated dose-dependent inhibition of hepatic glucose production. Metformin decreased glycogen synthesis in a dose-dependent manner [10] in cultured rat hepatocytes which are in agreement with the present study. Rhodiola crenulata root extract exert the glucose-lowering effect partly by inhibiting hepatic gluconeogenesis through activating the AMPK signaling pathway in the report of Lee et al. [11] which is in concurrence with the results of our study. In future plans, various spices [12] and medicinal plant like Kalanchoe pinnata [13] will be utilized to study their effects on in vitro isolated rat hepatocytes culture.

\section{CONCLUSION}

M. koenigii leaves may exert a cytoprotective effect on the normal rat hepatocytes in the ex vivo assay. Effects of the plant or isolated compounds on the genes expression of G6PAS, PEPCK, and AMPK signaling pathways should be investigated in the further study.

\section{ACKNOWLEDGMENT}

Authors acknowledge with gratitude to Dr. Suresh J. Bhosale and Research Fund Allotment Committee for providing financial assistance and facilities for to the $\mathrm{Ph}$. D research project.

\section{AUTHORS' CONTRIBUTION}

Rohan S. Phatak, Chitra C. Khanwelkar, Kailas D. Datkhile: Concept and Design, Rohan S. Phatak, Kailas D. Datkhile, Pratik Durgawale: Laboratory work. Rohan S. Phatak, Kailas D. Datkhile, Pratik Durgawale: Collection, Analysis and Interpretation of data. Rohan S. Phatak, Chitra C. Khanwelkar, Kailas D. Datkhile: Drafting of the Article. Rohan S. Phatak, Chitra C. Khanwelkar, Kailas D. Datkhile: Critical revision of intellectual contents and Final Approval of the article.

\section{CONFLICTS OF INTEREST}

The authors declare that they have no conflicts of interest.

\section{REFERENCES}

1. Xia X, Yan J, Shen Y, Tang K, Yin J, Zhang Y, et al. Berberine improves glucose metabolism in diabetic rats by inhibition of hepatic gluconeogenesis. PLoS One 2011;6:e16556.

2. Berasi SP, Huard C, Li D, Shih HH, Sun Y, Zhong W, et al. Inhibition of gluconeogenesis through transcriptional activation of EGR1 and DUSP4 by AMP-activated kinase. J Biol Chem 2006;281:27167-77.

3. Andrade-CettoA. Effects of medicinal plant extracts on gluconeogenesis. Botanics: Targets Ther 2012;2:1-6.

4. Srilatha BR, S Ananda. Antidiabetic effects of Mukia maderaspatana and its phenolics: An in vitro study on gluconeogenesis and glucose uptake in rat tissues. Pharm Biol 2014; 52:602.

5. Shen L, Hillebrand A, Wang DQ, Liu M. Isolation and primary culture of rat hepatic cells. J Vis Exp 2012;64: pii: 3917.

6. Mosmann T. Rapid colorimetric assay for cellular growth and survival: Application to proliferation and cytotoxicity assays. J Immunol Methods 1983;65:55-63.

7. Yan F, Zhang J, Zhang L, Zheng X. Mulberry anthocyanin extract regulates glucose metabolism by promotion of glycogen synthesis and reduction of gluconeogenesis in human hepG2 cells. Food Funct 2016;7:425-33.

8. Koti BC, Gore A, Thippeswamy AH, Swamy AH, Kulkarni R. Alcoholic leaf extract of Plectranthus amboinicus regulates carbohydrate metabolism in alloxan-induced diabetic rats. Indian J Pharmacol 2011;43:286-90

9. Cheng DM, Kuhn P, Poulev A, Rojo LE, Lila MA, Raskin I, et al. In vivo and in vitro antidiabetic effects of aqueous cinnamon extract and cinnamon polyphenol-enhanced food matrix. Food Chem 2012;135:2994-3002.

10. Otto M, Breinholt J, Westergaard N. Metformin inhibits glycogen synthesis and gluconeogenesis in cultured rat hepatocytes. Diabetes Obes Metab 2003;5:189-94.

11. Lee SY, Lai FY, Shi LS, Chou YC, Yen IC, Chang TC, et al. Rhodiola crenulata extract suppresses hepatic gluconeogenesis via activation of the AMPK pathway. Phytomedicine 2015;22:477-86.

12. Phatak RS, Pratinidhi AK, Hendre AS. Screening of some Indian household spices for comparative studies of antioxidant and antiradical activities by using in-vitro models. Asian J Pharm Clin Res 2015;8:431-8.

13. Phatak RS, Hendre AS. Green synthesis of silver nanorods using aqueous extract of Kalanchoe pinnata fresh leaves and its synergistic effect with ciprofloxacin and antibiofilm activities. Int J Pharm Pharm Sci 2016;8:168-74. 